\title{
Pengaruh Total Solid dan Perbandingan Bahan Baku dengan Inokulum terhadap Produksi Biogas dari Jerami Jagung
}

\author{
Gita Indah Budiarti a,1,*, Lukhi Mulia Shitophyta ${ }^{\text {b,2 }}$, Dika Fajariyanto ${ }^{\text {b,3 }}$, Yusuf Eko Nugroho ${ }^{\text {b,4 }}$ \\ ${ }^{a}$ Program Studi Teknik Kimia FTI UAD, Kampus III, Jl. Supomo, Janturan, Warungboto, Yogyakarta, 55164 \\ ${ }^{1}$ gita.indah@che.uad.ac.id*
}

ARTICLE INFO

Article history

Received May 14, 2018

Revised September 07, 2018

Accepted September 09, 2018

Keywords

Anaerobic digestion

Biogas

Corn stover

Solid-state

\section{AB STRACT}

Biogas is an environmentally friendly alternative energy that can be used for energy needs in Indonesia. The effect of total solid (TS) content and feedstock/inoculum (F/I) ratio on biogas production from corn stover by solid-state anaerobic digestion (SS-AD) were studied. At a F/I ratio of 2, conversion of corn stover under room temperature resulting in higher biogas yield. SS-AD performed as expected at the TS content of $20 \%, 22 \%, 24 \%$. The highest biogas yield of $200 \mathrm{~L} \mathrm{~kg}-1$ volatile solids (VS) was obtained at TS content of 22\%, F/I ratio of 2 .

This is an open access article under the CC-BY-SA license.

\section{Pendahuluan}

Kebutuhan energi di Indonesia pada tahun 2015 sampai 2018 diperkirakan mengalami peningkatan. Konsumsi energi di Indonesia sebagian besar adalah energi listrik dan bahan bakar. Sumber energi untuk listrik dan bahan bakar kendaraan diperoleh dari bahan bakar minyak (BBM). BBM merupakan bahan bakar fosil yang tidak bisa diperbarui, jika digunakan terus menerus akan habis. Oleh karena itu dibutuhkan energi alternatif yang dapat diperbaharui sebagai pengganti BBM [1]. Salah satu energi yang dapat diperbaharui adalah biogas. Biogas adalah campuran gas yang dibuat dengan cara anaerob digestion, penyusun utamanya adalah gas metana $\left(\mathrm{CH}_{4}\right)$ dan karbon dioksida $\left(\mathrm{CO}_{2}\right)$. Gas metana yang dihasilkan biogas dapat digunakan sebagai sumber energi di wilayah pedesaan [2].

Keunggulan dari biogas ini adalah ramah lingkungan karena bahan baku berupa limbah organik, misalnya limbah hasil pertanian, limbah buah-buahan dan limbah sisa makanan. Beberapa penelitian terkait biogas sudah pernah dilakukan diantaranya, Budiyono et al [1] meneliti tentang pengaruh jenis inokulum terhadap produksi biogas dari sampah buah-buahan. Inokulum yang digunakan adalah rumen sapi. Produksi jagung di Indonesia mencapai 13 juta ton per tahun [3]. Jagung menghasilkan jerami jagung sekitar $29 \%$ sehingga jerami jagung merupakan biomassa yang tersedia melimpah di dunia. Sepertiga jerami jagung pada umumnya hanya ditinggalkan di ladang untuk dibakar sehingga berpotensi terjadinya polusi udara, kebakaran bahkan dapat menganggu keselamatan lalu lintas [4].

Biogas dibuat di dalam digester secara anaerob merubah bahan organik menjadi gas metana dengan bantuan bakteri [2]. Proses anaerob digestion terdiri dari tiga tahap. Tahap pertama, mikroorganisme menyerang bahan yang terdiri dari senyawa organik kompleks, seperti selulosa dan pati menjadi monomer. Monomer tersebut menjadi substrat untuk mikroorganisme, tahap kedua monomer di tahap pertama dirubah menjadi asam asetat. Tahap terakhir, bakteri metagenesis berubah menjadi metana melalui dua mekanisme yaitu fermentasi asam asetat dan reduksi gas $\mathrm{CO}_{2}$ menggunakan $\mathrm{H}_{2}$. Kecepatan produksi biogas dipengaruhi beberapa faktor antara lain, substrat, temperatur, $\mathrm{pH}$, pengadukan, toksisitas, nutrien, konsentrasi slurry, konstruksi digester, rasio karbon 
dan nitrogen $(\mathrm{C} / \mathrm{N})$, waktu retensi, total asam volatile, chemical oxygen demand (COD), total solid (TS), volatile liquid (VS) [5].

Proses anaerobic digestion dapat digolongkan menjadi dua macam berdasarkan kandungan total solid (TS) yaitu liquid anaerobic digestion untuk kandungan TS kurang dari 15\%, sedangkan kandungan TS lebih besar dari 15\% menggunakan proses solid-state anaerobic digestion (SS-AD) [6]. Yang, et al [7] menyatakan bahwa volume produksi biogas dengan SS-AD menghasilkan volume lebih banyak dibandingkan dengan L-AD. Keuntungan lain dari SS-AD antara lain: volume reaktor lebih kecil, tidak membutuhkan pengadukan, dan kebutuhan air lebih sedikit [8]. Keseimbangan jumlah mikroba dipengaruhi oleh perbandingan F/I, sedangkan kinerja proses dan jumlah yield biogas dipengaruhi oleh kandungan TS [9,10]. Penelitian tentang produksi biogas dari limbah pertanian yang telah dilakukan sebelumnya adalah pembuatan biogas menggunakan metode yang liquid anaerobic digestion. Penelitian yang dilakukan saat ini produksi biogas dari jerami jagung menggunakan metode SS-AD. Penelitian ini bertujuan untuk menentukan pengaruh rasio F/I, kandungan TS terhadap yield biogas dari jerami jagung.

\section{Metode Penelitian}

\subsection{Alat dan Bahan}

Alat-alat yang digunakan pada penelitian adalah batch digester $1,5 \mathrm{~L}$, gelas ukur, $\mathrm{pH}$ meter, statif, penjepit, dan selang. Bahan yang digunakan pada penelitian ini adalah jerami jagung sebagai bahan baku, cairan rumen sapi sebagai inokulum, $\mathrm{NaOH}$ sebagai pengatur $\mathrm{pH}$ dan aquades.

\subsection{Persiapan Bahan Baku dan Inokulum}

Jerami jagung dikeringkan, kemudian dipotong 2-3 cm dan disimpan pada suhu kamar. Inokulum yang digunakan dalam keadaan segar.

\section{Solid-state anaerobic digestion}

Pada penelitian ini digunakan batch digester 1,5 L. Bahan baku dan inokulum diumpankan pada digester dengan dengan masing-masing variasi rasio F/I 2, 3, 4, variasi kandungan TS 20\%, 22\%, 24\%. Air ditambahkan untuk mengatur kandungan TS $\mathrm{pH}$ awal pada digester adalah 7 dengan menambahkan larutan $\mathrm{NaOH}$ [11].

Percobaan dilakukan pada temperatur kamar. Digester ditutup dengan sumbat karet dan bagian tengah sumbat karet diberi lubang untuk memasukkan selang di dalam masing-masing digester. Selanjutnya, dilapisi dengan isolatip agar digester tertutup rapat. Selang berfungsi untuk mengalirnya biogas yang terbentuk. Gelas ukur diletakkan pada statif dan penjepit untuk mengukur volume biogas dengan water-displacement method [12]. Volume biogas diukur 2-3 hari sekali.

\section{Hasil dan Pembahasan}

\subsection{Pengaruh Kandungan TS}

Gambar 1 menunjukkan yield biogas harian dari jerami jagung dengan variasi kandungan TS. Pada temperatur ruang $\left( \pm 30^{\circ} \mathrm{C}\right)$ proses solid-state anaerobic digestion (SS-AD) dengan kandungan TS 20, 22 dan 24\%. Biogas terbentuk di hari ke 5, meningkat secara perlahan sampai hari ke 15 untuk TS 20 dan 22\%. Yield biogas harian dari hari ke 15-20 mengalami peningkatan yang signifikan atau mencapai peak maksimal untuk TS 20 dan $22 \%$ sebesar $40 \mathrm{~L} / \mathrm{kg}$ VS dan $45 \mathrm{~L} / \mathrm{kgVS}$ berurutan. Peak maksimal TS 24\% diperoleh antara 10-15 hari sebesar $30 \mathrm{~L} / \mathrm{kg}$ VS. Yield biogas kumulatif terbesar diperoleh pada TS $22 \%$ yaitu $200 \mathrm{~L} / \mathrm{kg}$ VS (Gambar 2). Yield biogas kumulatif terendah terendah diperoleh $80 \mathrm{~L} / \mathrm{kg}$ VS pada TS $24 \%$. Nilai yield yang rendah pada kandungan TS yang tinggi dipengaruhi oleh penghambatan tahap metanogenesis karena munculnya volatile fatty acid pada tahap awal, saat memasukkan jumlah bahan baku (padat) dalam jumlah yang besar. Kondisi kandungan TS maksimal 22\% selanjutnya digunakan pada percobaan penentuan pengaruh variasi F/I terhadap yield biogas. 


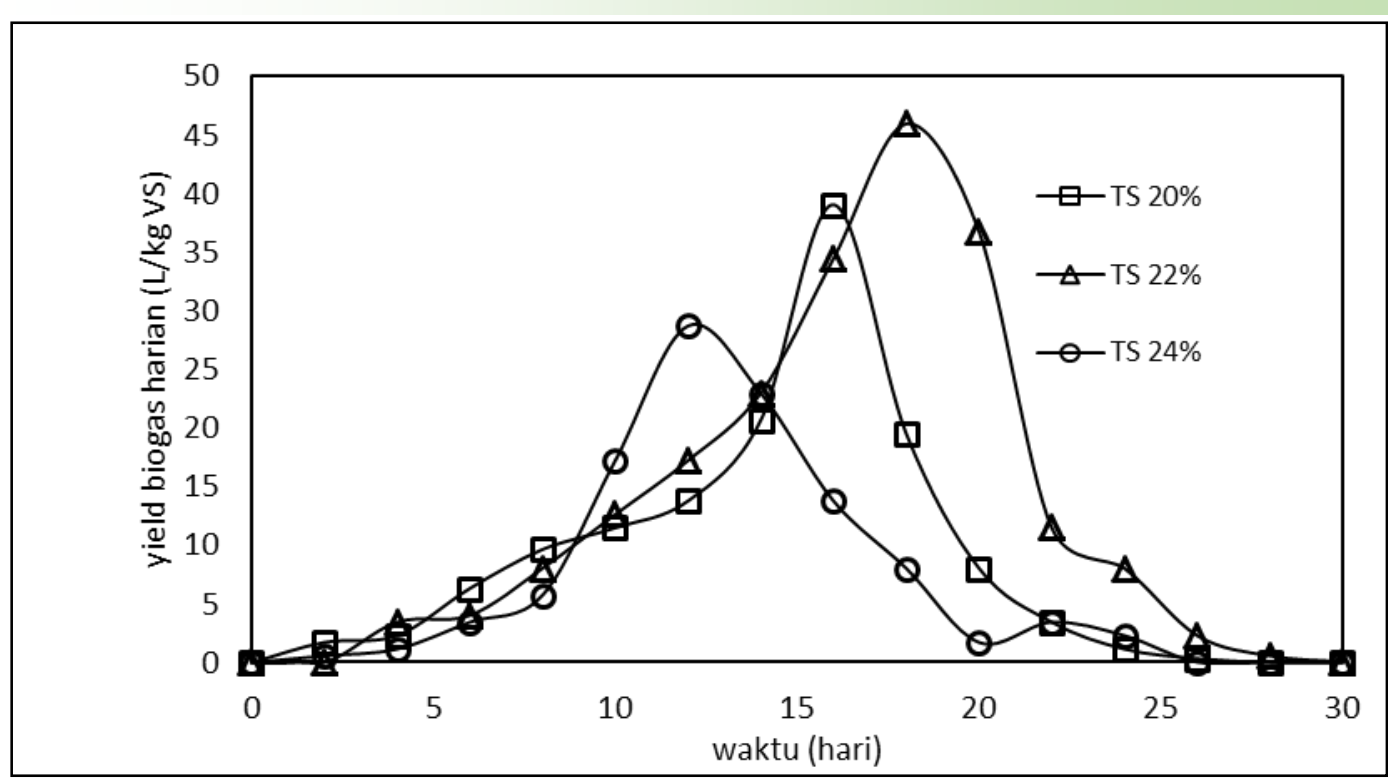

Gambar 1. Yield Biogas Harian pada Variasi Kandungan TS

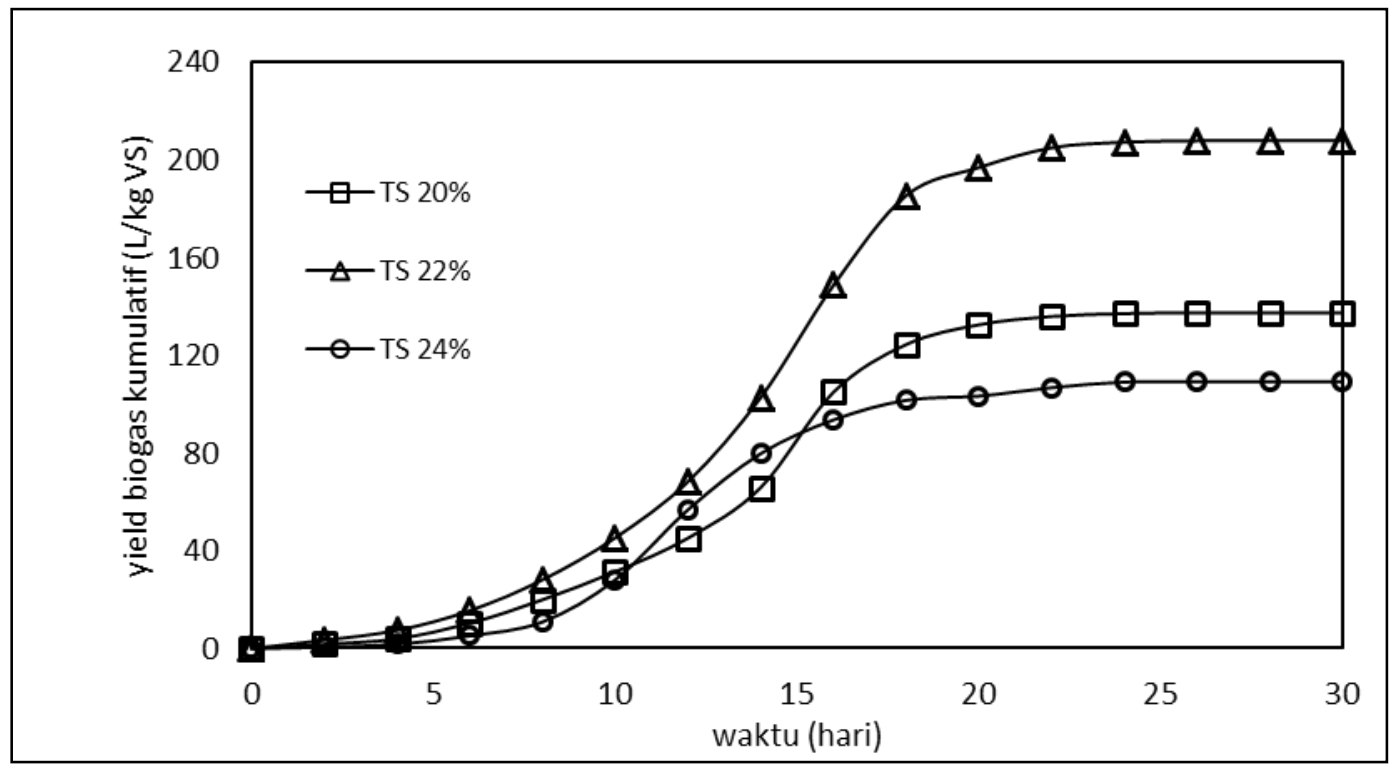

Gambar 2. Yield Biogas Kumulatif pada Variasi Kandungan TS

\subsection{Pengaruh Perbandingan $\mathrm{F} / \mathrm{I}$}

Pengaruh perbandingan F/I pada yield biogas harian menggunakan proses SS-AD dengan TS $22 \%$ di bawah kondisi suhu ruang itunjukkan pada Gambar 3. Pada hari pertama terjadi peak kecil dan meningkat namun tidak signifikan sampai hari ke 13. Peak yang diperoleh ini merupakan tahap degradasi bahan baku. Pada hari ke 15, F/I 3 dan 4 mengalami peningkatan sampai peak maksimalnya yaitu $38 \mathrm{~L} / \mathrm{kg}$ VS dan $28 \mathrm{~L} / \mathrm{kg}$ VS berurutan. Pada hari ke 16, F/I 3 dan 4 mengalami penurunan, sedangkan F/I 2 mengalami peak maksimal sebesar $45 \mathrm{~L} / \mathrm{kg}$ VS. Yield biogas terbesar diperoleh pada perbandingan F/I terkecil yaitu 2. Hubungan antara perbandingan F/I dan yield berbanding terbalik, karena aktivitas methanogenic dan bilangan methanogens yang rendah di dalam digester menyebabkan timbulnya akumulasi volatile fatty acid (VFA) selama tahap acidogenic [7,10]. Konsentrasi VFA yang tinggi menjadi inhibitor terhadap bakteri methanogenesis. Penelitian sebelumnya yang dilakukan Li, et al [10] pada pembuatan biogas yang juga menggunakan jerami jagung dan penelitian Yang, et al [7] menggunakan bahan baku limbah makanan juga memperoleh hasil yield biogas terbesar pada perbandingan F/I terendah. Perkiraan bahwa tahap hidrolisis atau acidogenesis dihambat dengan tingginya perbandingan $\mathrm{F} / \mathrm{I}$ belum dikaji pada penelitian ini. 
Pengaruh perbandingan F/I terhadap yield biogas disajikan pada Gambar 4. Hasil yang sama ditunjukkan pada yield biogas kumulatif, yield terbesar adalah $200 \mathrm{~L} / \mathrm{kg}$ VS diperoleh pada perbandingan F/I 2. Yield biogas kumulatif terendah diperoleh pada perbandingan F/I terbesar 4 sebesar $100 \mathrm{~L} / \mathrm{kg}$ VS. Semakin besar prbandingan F/I, yield biogas semakin kecil, baik yield harian maupun yield kumulatif.

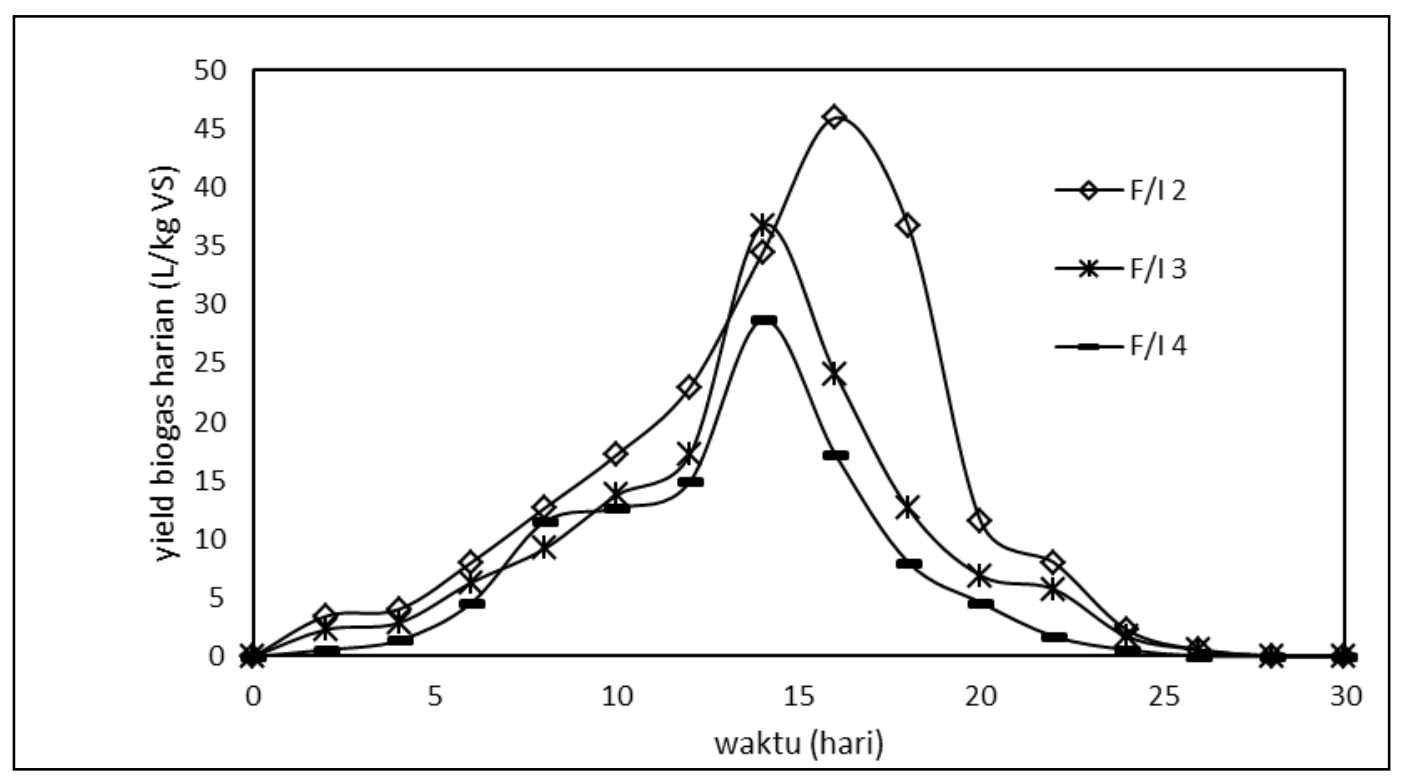

Gambar 3. Yield Biogas Harian pada Variasi Perbandingan F/I

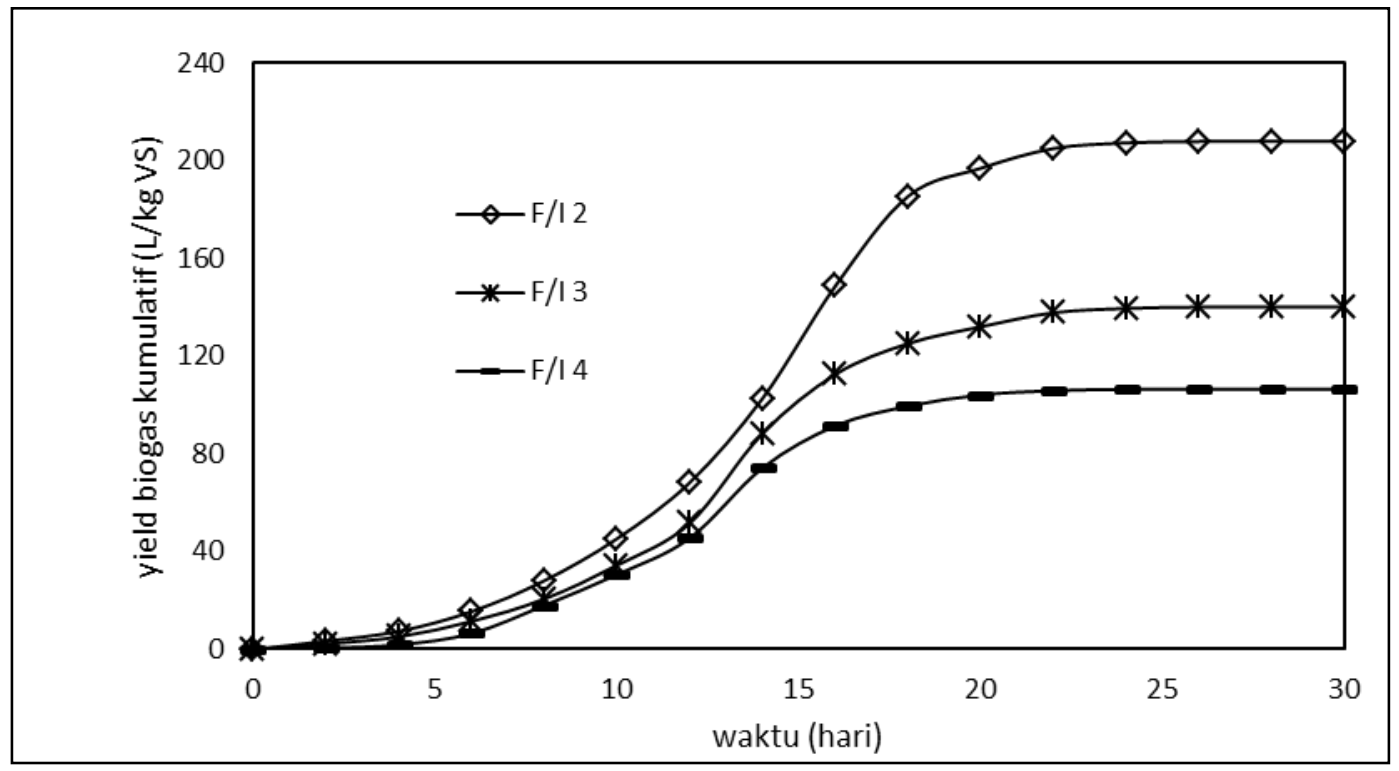

Gambar 4. Yield Biogas Kumulatif pada Variasi Perbandingan F/I

\section{Kesimpulan}

Penelitian pembuatan biogas dari jerami jagung menggunakan metode SS-AD diperoleh kesimpulan bahwa pengaruh kandungan TS dan perbandingan F/I terhadap yield biogas adalah semakin rendah maka yield biogas semakin tinggi. Yield kumulatif dan harian terbesar diperoleh pada kandungan TS terbesar adalah $22 \%$ dan perbandingan F/I 2 yaitu 200L/kg VS dan $45 \mathrm{~L} / \mathrm{kg} \mathrm{VS}$. 


\section{Ucapan Terimakasih}

Terimakasih kepada DRPM DIKTI yang telah memberikan dana bantuan penelitian sehingga penelitian ini dapat terlaksana.

\section{Daftar Pustaka}

[1] Budiyono., Manthia F , Amalin N, Hawali Abdul Matin H, and Sumardiono S, 2018. Production of Biogas from Organic Fruit Waste in Anaerobic Digester using Ruminant as The Inoculum. MATEC Web of Conferences 156, 03053 (2018) pp 1-5.

[2] Santos, I F S., Vieira, N D B., Nóbrega, L GB., Barros, R B., Filho, G L T., 2018. Assessment of potential biogas production from multiple organic wastes in Brazil: Impact on energy generation, use, and emissions abatement. Resources, Conservation \& Recycling 131 (2018).pp 54-63.

[3] Badan Pusat Statistik Indonesia. 2016. "Food Crops" (http://www.bps.go.id/eng/tnmn_pgn.php?kat=3), diakses tanggal 25 Februari 2017.

[4] Chen, G., Zheng, Z., Yang, S., Fang, C., Zou, X., \& Luo, Y., 2010. Experimental co-digestion of corn stalk and vermicompost to improve biogas production. Waste Management, 30(10). pp 1834-1840.

[5] Sagagi, B. S., B. Garba and N. S. Usman. 2009. Studies On Biogas Production From Fruits And Vegetable Waste. Bayero Journal of Pure and Applied Sciences, 2(1), pp.115 - 118.

[6] Lin, Y., Ge, X., \& Li, Y. 2014. Solid-state anaerobic co-digestion of spent mushroom substrate with yard trimmings and wheat straw for biogas production. Bioresource Technology, 169, 468-474.

[7] Yang, L., Xu, F., Ge, X., Li,Y., 2015. Challenges and strategies for solid-state anaerobic digestion of lignocellulosic biomass. Renewable and Sustainable Energy Reviews 44 (2015). pp.824-834.

[8] Yan, Z., Song, Z., Li, D., Yuan, Y., Liu, X., \& Zheng, T. 2015. The effects of initial substrate concentration, $\mathrm{C} / \mathrm{N}$ ratio, and temperature on solid-state anaerobic digestion from composting rice straw. Bioresource Technology, 177, pp. 266-273.

[9] Khalid, Azeem, Muhammad Arshad, Muzammil Anjum, Tariq Mahmood, and Lorna Dawson. 2013. "Table of Contents The Anaerobic Digestion of Solid Organic Waste." Waste Management, 31(8), $1737-1744$.

[10]Li, Y., Zhu, J., Wan, C., \& Park, S. Y. 2011b. Solid-state anaerobic digestion of corn stover for biogas production. American Society of Agricultural and Biological Engineers, 54(4), 1415-1421.

[11] Kim, M., Yang, Y., Morikawa-Sakura, M. S., Wang, Q., Lee, M. V, Lee, D.-Y., et al. 2012. Hydrogen production by anaerobic co-digestion of rice straw and sewage sludge. International Journal of Hydrogen Energy, 37(4), 3142-3149.

[12] Budiyono, Syaichurrozi, I., \& Sumardiono, S. 2014. Effect of total solid content to biogas production rate from vinasse. International Journal of Engineering, 27(2), 177-184. 